
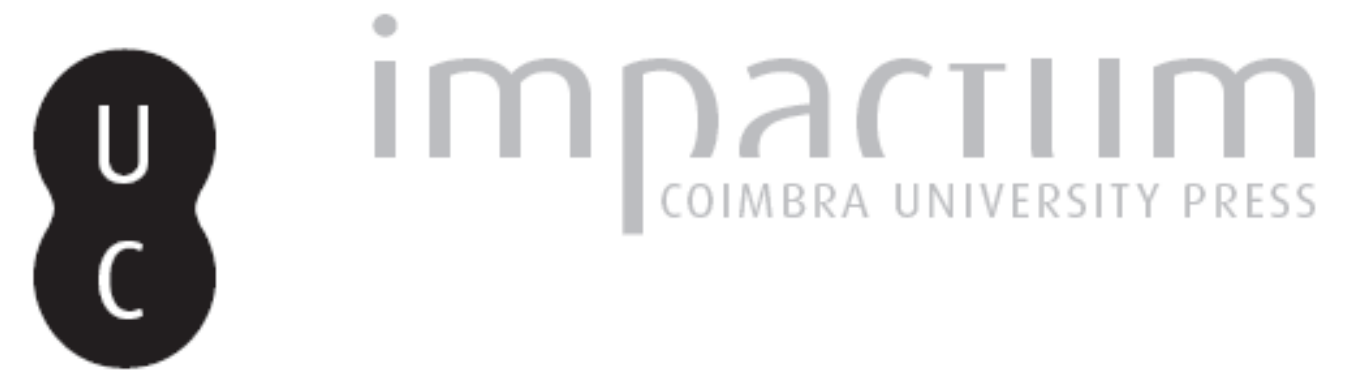

Wittenberg e Roma na via do diálogo 500 anos após o início da Reforma de Lutero

Autor(es): $\quad$ Rodrigues, Manuel Augusto

Publicado por: Imprensa da Universidade de Coimbra

URL persistente:

URI:http://hdl.handle.net/10316.2/40221

DOI:

DOI:https://doi.org/10.14195/2183-8925_34_12

Accessed : $\quad$ 26-Apr-2023 14:43:11

A navegação consulta e descarregamento dos títulos inseridos nas Bibliotecas Digitais UC Digitalis, UC Pombalina e UC Impactum, pressupõem a aceitação plena e sem reservas dos Termos e Condições de Uso destas Bibliotecas Digitais, disponíveis em https://digitalis.uc.pt/pt-pt/termos.

Conforme exposto nos referidos Termos e Condições de Uso, o descarregamento de títulos de acesso restrito requer uma licença válida de autorização devendo o utilizador aceder ao(s) documento(s) a partir de um endereço de IP da instituição detentora da supramencionada licença.

Ao utilizador é apenas permitido o descarregamento para uso pessoal, pelo que o emprego do(s) título(s) descarregado(s) para outro fim, designadamente comercial, carece de autorização do respetivo autor ou editor da obra.

Na medida em que todas as obras da UC Digitalis se encontram protegidas pelo Código do Direito de Autor e Direitos Conexos e demais legislação aplicável, toda a cópia, parcial ou total, deste documento, nos casos em que é legalmente admitida, deverá conter ou fazer-se acompanhar por este aviso.

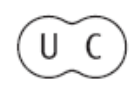



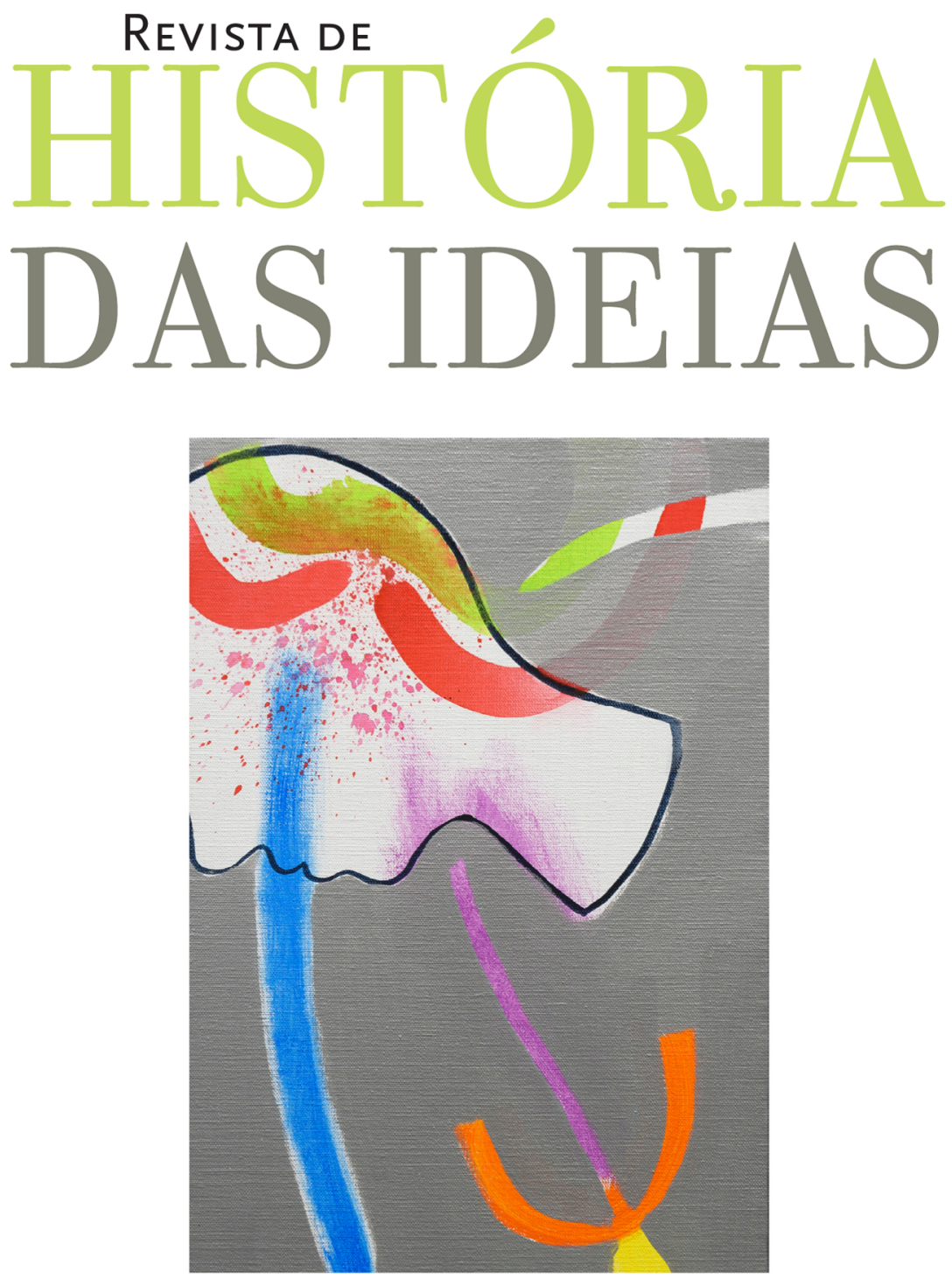

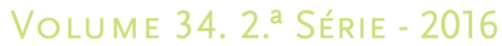




\title{
WITTENBERG E ROMA NA VIA DO DIÁLOGO 500 ANOS APÓS O INÍCIO DA REFORMA DE LUTERO ${ }^{(1)}$
}

\section{WITTENBERG AND ROME ON THE DIALOGICAL WAY 500 YEARS} AFTER THE LUTHER'S REFORMATION

\author{
Manuel Augusto Rodrigues \\ marodrigues@ci.uc.pt \\ Universidade de Coimbra - IHTI \\ Texto recebido em / Text submitted on: 20/06/2016 \\ Texto aprovado em / Text approved on: 23/09/2016
}

\section{Resumo:}

Com este contributo pretende-se evocar os 500 anos da Reforma de Lutero. Importa antes de mais falar da personalidade do «pai» do histórico movimento

(1) O presente artigo vem na sequência do que publicámos na Revista de História da Sociedade e da Cultura, 15 (2015), p. 171-189, intitulado «Da Hermenêutica da Controvérsia Luterano-Católica ao Diálogo Contemporâneo. O 5. ${ }^{\circ}$ Centenário das 95 Teses de Lutero» à luz do documento Do Conflito à Comunhão. Comemoração Conjunta Luterano-católica da Reforma em 2017 (2013)». Esta declaração entre o Vaticano e a Federação Luterana Mundial (LWB), com 90 páginas, em seis capítulos, 245 artigos e 90 notas explicativas, constitui uma excelente súmula dos temas principais acerca de Lutero e da Reforma e do estado atual das relações luterano-católicas, na circunstância da evocação do $5^{\circ}$ centenário das 95 Teses de Lutero. Lê-se no início do texto: «Esta evocação tem lugar em tempo de ecumenismo e de mundialização (§§ 4-15) e quando estamos em presença de novos pontos de vista sobre Martinho Lutero e a Reforma (\$§ 16-34)». O cap. III traça um esboço histórico da Reforma luterana e da reação católica (\$§ 35-90), o cap. IV apresenta os temas principais da teologia de Lutero à luz dos diálogos luterano-católicos (§§ 91-218) e os cap. V e VI, falam, respetivamente, da comemoração comum (\$§ 219-237) e de cinco imperativos ecuménicos (\$§ 238-245). 
que se revestiu de enorme importância para a Europa, particularmente do Norte e de Leste, e também para o mundo. Entre outros seus colaboradores salientouse Melanchton, o "praeceptor Germaniae», aquele que elaborou a primeira sistematização teológica da Reforma. Passados cinco séculos de duras tomadas de posição entre Wittenberg e Roma, constata-se que de há cerca de 50 a esta parte as duas confissões cristãs encetaram um diálogo frutuoso cujos resultados estão à vista. Alguns documentos como o Do Conflito à Comunhão (2013) abriram novos caminhos para reavaliar o passado e perspetivar o futuro. Reputados autores têm escrito importantes livros e artigos que mostram à evidência estarmos a assistir a uma mudança profunda de paradigma nas relações luterano-católicas correspondendo assim aos sinais dos tempos.

\title{
Palavras-chave:
}

Cochlaeus, Ecumenismo, Lutero (1517-2017), Mística, Reforma.

\begin{abstract}
:
The aim of the present article is to evoke the 500 years of the Luther's Reformation. First of all it is important to talk about the personality of the «father» of the historical movement which had a great meaning for Europe, particularly the septentrional and oriental countries, and also for the world. Among other Luther's collaborators we must evidence Melanchton, the "praeceptor Germaniae», the man who elaborated the first Reformation's theological systematization. After five centuries of hard controversies it is to register that since about 50 years the two parts, the protestant and the catholic, developed a fructiferous dialogue whose results are very positive. Some documents like From Conflict to Communion opened new ways to reexamine the past and to build bridges in order to defy the future with firm hope. Credited authors underline that the times have changed.
\end{abstract}

\section{Keywords:}

Cochlaeus, Luther (1517-2017), Mystic, Oecumenism, Reformation.

\section{Introdução}

No próximo dia 31 de outubro terá lugar na catedral de Lund (Suécia) uma celebração ecuménica evocativa do $5 .^{\circ}$ centenário da Reforma de Lutero $^{(2)}$, na qual participarão os representantes máximos do Luterischer

(2) Lutero nasceu a 10 de novembro de 1483 na cidade de Eisleben (Saxónia, Santo Império Romano), onde veio a morrer a 18 de fevereiro de 1546 . Além de An den christlichen Adel deutscher Nation, Von der babylonischen Gefangenschaft der Kirche, Von der Freiheit eines 
Weltbund (LWB) e também o Papa de Roma ${ }^{(3)}$. O evento marca oficialmente o início do jubileu da Reforma, ocorrido em 31 de outubro de 1517. Se há 500 anos um Papa excomungava Lutero, agora Roma e Wittenberg irão afirmar o propósito de contribuir para um virar de página começado há mais de 50 anos e que o Concílio Vaticano II sancionou. Trata-se de uma caminhada longa com inúmeros problemas a resolver, depois de cinco séculos da separação iniciada com a publicação das 95 Teses e com a Bula Exsurge Domine de Leão $X^{(4)}$, de 15 de junho de 1520, que condenou 41 teses de Lutero, a que se seguiu em 3 de janeiro a Bula Decet Romanum Pontificem que excomungava definitivamente o pai da Reforma. Também o imperador o expatriou do seu território, mas o príncipe-eleitor da Saxónio acolheu-o no seu castelo de Wartburgo. Não entramos aqui no enunciado de acontecimentos importantes de ordem religiosa, política, social e cultural, nas polémicas permanentes e na atitude apologética que marcaram a implantação da Reforma e em que intervieram personalidades de relevo como Melanchton ${ }^{(5)}$. As guerras religiosas, as disputas teológicas

Christenmens e De sevo arbitrio, deixou uma vasta obra sobre temas teológicos, bíblicos e outros. De recordar o impacto que a Reforma teve na Inglaterra desde o reinado de Henrique VIII dando origem ao anglicanismo. Na polémica entretanto surgida sobressaíram do lado católico figuras gradas como o célebre humanista Thomas More (6 de fevereiro de 1477?-6 de julho de 1535), autor da Utopia e grande amigo de Erasmo (27-28 de outubro de 1467?12 de julho de 1536) e W. Tyndale (1484-6 de outubro de 1536) que traduziu quase toda a Bíblia para inglês (o Novo Testamento foi impresso em Worms em 1526). O trabalho de Tyndale foi decisivo para a Authorized King James (1611).

(3) O Luherischer Weltbund (LWB), em inglês Lutheran World Federation (LWF), é uma comunidade de Igrejas luteranas criada em Lund (Suécia) em 1947. Dela fazem parte cerca de 145 Igrejas que contam mais de 72 milhões de fiéis espalhados por 98 países. O LWB resultou do Lutherischer Weltkonvent fundado em 1923.

(4) Leão X, nascido João de Lourenço de Médicis (em italiano Giovanni di Lorenzo de Medici) viveu entre 11 de dezembro de 1475 e 1 de dezembro de 1521 e foi testemunha dos inícios da Reforma Protestante. Era o segundo filho de Clarice Orsini e Lorenzo de Medici, o governante mais famoso da República de Florença. Seu primo, Giulio di Giuliano de Medici, viria a suceder-lhe como Papa Clemente VII (1523-34). Giovanni recebeu uma cuidadosa educação na corte de Lorenzo, foi colega de humanistas como Angelo Poliziano, Pico della Mirandola, Marsilio Ficino e Bernardo Dovizio Bibbiena. Entre 1489 e 1491 estudou teologia e Direito Canónico em Pisa sob a orientação de Filipe Decio.

(5) Filipe Melanchton, propriamente Philipp Schwartzerdt (Bretten, 16 de fevereiro de 1497 - Wittenberg, 19 de abril de 1560) evidenciou-se como filólogo, filósofo, humanista, teólogo e poeta neolatino. Professor universitário e reformador ao lado de Lutero, tornou-se conhecido pelo epíteto de «educador da Alemanha» («Lehrermeister Deutschlands», «praeceptor Germaniae») por ter organizado e reformado as escolas alemãs. O mesmo epíteto já fora atribuído a Rabanus Maurus (ca. 780-856), intelectual alemão e arcebispo de Mogúncia, e voltou a sê-lo a Siegbert Tarrasch (1862-1934), jogador 
e outras, as condenações bastante duras de parte a parte caracterizaram um longo período que ficou assinalado por sequelas não só na Alemanha como também noutros países e continentes. O Concílio de Trento (15451563) e a Contrarreforma foram pelo lado católico as duas referências mais relevantes até ao Concílio Vaticano $\mathrm{II}^{(6)}$.

Mas o legado do ilustre professor de Wittenberg manteve-se vivo e continua a merecer dos fiéis e estudiosos o maior interesse. Nunca será exagerado sublinhar o valioso contributo da Reforma não só no campo religioso privilegiando a Fé (salvação pela Fé segundo Rom 1, 17) e a Palavra de Deus, como também nas diversas áreas da cultura e noutros domínios. A tradução da Bíblia para alemão que contribuiu para a fixação da língua alemã moderna, os catecismos e tantos escritos que foram sendo produzidos em vários idiomas emprestaram aos povos evangelizados um inestimável tesouro para a sua promoção cultural ${ }^{(7)}$. Lembre-se igualmente a valorização da música sacra para uso litúrgico. O próprio Lutero compôs corais em alemão (Recueil de Wittenberg e Psautier huguenot) e Bach foi o principal compositor de corais luteranos.

A LWB e a Igreja de Roma têm mantido durante os últimos 50 anos um diálogo frutífero de que são testemunho alguns documentos aprovados

de xadrez. Desgostava-o o baixo nível da instrução nas escolas alemãs durante a Idade Média, sentimento expresso no seu De Miseriis paedagogorum, livro em que relata o triste estado em que se encontrava a Alemanha. Deixou uma obra notável de que se destacam Institutiones graecae grammaticae 1518; Loci communes rerum theologicarum 1521; Unterricht der Visitatoren an die Pfarrherren im Kurfürstentum Sachsen 1527; Confessio Augustana 1530; Apologie der Confessio Augustana 1531; Tractatus de potestate et primatu Papae (Traktat über die Gewalt und den Primat des Papstes) 1537.

(6) Salientamos os seguintes documentos indicando os temas neles tratados: Dei Verbum (Palavra de Deus), Lumen gentium (Igreja), Sacrosanctum Concilium (Liturgia), Gaudium et spes (A Igreja no mundo contemporâneo), Nostra Aetate (A Igreja e as religiões não cristãs ), Dignitatis humanae (Liberdade religiosa) e Unitatis redintegratio (Ecumenismo).

(7) Rómulo de Carvalho no seu livro História do Ensino em Portugal (1986). Lisboa, Fundação Calouste Gulbenkian, 711, nota 67, ao tratar do analfabetismo em Portugal diz: «Os valores numéricos relativos ao analfabetismo nos diversos países europeus demonstram irrefutavelmente a influência que sobre eles tem a opção religiosa. Em 1881, o número de analfabetos na Suécia, nação protestante, cifrava-se em 0,4\%. Em 1881! Pela mesma época a Alemanha apresentava 0,51\%, a Inglaterra e a Escócia 1,00\%; a Noruega, 0,08\% e a Dinamarca, $0,36 \%$. Tudo países de religião protestante. Nos países de religião católica, como Portugal, eram, na mesma altura do século XIX, 68\% em Espanha, 42\% na Itália, 38\% na Áustria, 28\% na Irlanda e 17\% na Bélgica» (em Portugal a taxa era, em 1911, de 75,1\%). Rómulo de Carvalho recolheu esses números de Salvado Sampaio (O Ensino Primário I, 79) que os transcreve de Agostinho de Campos (Educação e Ensino, Porto, 1911, 249, acrescentando que este último autor atribui à Companhia de Jesus a responsabilidade da elevada taxa de analfabetismo. 
pela Comissão luterano-católica que, desde 1980, tem realizado um importantíssimo trabalho ${ }^{(8)}$. As duas confissões participaram nas evocações dos 450 anos da Confissão de Augsburgo (1530) e do centenário do nascimento de Lutero em $1983^{(9)}$. Os resultados mais significativos encontram-se na Declaração conjunta sobre a doutrina da justificação, oficialmente assinada em 1999, que foi aceite pelo Conselho metodista mundial em 2006. Esta declaração pôs termo ao contencioso fundamental sobre um tema complexo que fazia parte importante da Reforma do séc. XVI. Foi um passo decisivo que, além de dar a esperança da unidade das Igrejas cristãs, em particular a anglicana e a ortodoxa, permitiu também abrir o caminho para a celebração comum entre protestantes e católicos do único Senhor da Igreja. Neste contexto importa referir que um dos pontos chave é o da evolução do dogma ao qual os teólogos têm sabido responder de forma convincente e sensata ${ }^{(10)}$.

Se é certo que aquilo «que aconteceu no passado não pode ser alterado, também é certo que aquilo que se recorda do passado e o modo como sucedeu, pode no decurso do tempo ser modificado», lê-se no Documento do Conflito à Comunhão (2013) de que se falará mais adiante:

O que aconteceu no passado não pode ser alterado. Mas aquilo que se recorda do passado e o modo como sucedeu, pode no decurso do tempo ser modificado. A recordação torna presente o passado. Enquanto o passado é imutável, já a presença do passado no presente pode ser

(8) Vários foram os relatórios e textos relativos a Lutero e a Melanchton de entre os quais destacamos: «Martinho Lutero, testemunha de Jesus Cristo. Declaração para o $500^{\circ}$ aniversário de Lutero» (1983), Documentation catholique 1983, 694-697; «Face à unidade: modelos, formes e etapas da comunhão eclesial luterano-católica» (1985), Documentation catholique 1987, 294-319; «Igreja e justificação» (1993), Documentation catholique 1994, 810-858; «A Apostolicidade da Igreja» (2007), Serviço Informação 128, 2008/ I-II; «Declaração comum sobre a doutrina da justificação», assinada por representantes da Igreja católica e da LWB a 31 de outubro de 1999; e o já referido «Do Conflito à Comunhão» (2013). Finalmente, em 31 de outubro de 2015 a Conferência Episcopal dos Estados Unidos e a Igreja Evangélica Luterana aprovaram a «Declaração ao longo do caminho» («Declaration on the way»).

(9) A Herzog-August Bibliothek de Wolfenbüttel organizou em 1983 vários actos comemorativos dessa efeméride. Importante é o Katalog der Wolfenbütteler Luther-Drucke 1513 bis 1546 elaborado por Maria von Katte. Datenbank von Christian Knoop. Wolfenbüttel, Herzog August Bibliothek, 2006.

(10) Ver os trabalhos de K. Rahner, Zur Frage der Dogmenentwicklung, Schriften zur Theologie 1, 2. ${ }^{\text {a }}$ ed., 49-90; G. Thils, «L'Evolution du dogme dans la theologie catholique», Études Téologiques Louvanienses 28 (1952), 679-682; H. Walgrave, «Newman. Le développement du dogme», Revue de l'histoire des religions 155, nº 2 (1959), 260-261. 
alterada. Olhando para 2017 trata-se não de escrever outra história, mas de a narrar de forma diferente (II, 16) $)^{(11)}$.

\section{De Martinho Lutero, um destino, da autoria de Lucien Febvre (1928), ao discurso do Papa Bento XVI em Erfurt (2011)}

Sobre o monge agostinho de Erfurt escreveu Lucien Febvre, em 1928, o famoso livro, intitulado Martin Luther, un destin, acerca do qual Johann Chapoutot teceu em 2013 um excelente comentário ${ }^{(12)}$ que aqui transcrevemos. Depois de encarecer o notável papel de Lucien Febvre na "École des Annales" Chapoutot evidencia alguns aspectos interessantes:

En 1917, Lucien Febvre a suivi avec intérêt les commémorations qui ont marqué les 400 ans des 95 thèses de Wittenberg, date de naissance de la réforme luthérienne. Contre la légende noire d'un Luther démoniaque, promue par les catholiques, et la légende dorée du héros allemand, Febvre part à la recherche d'un Luther plus authentique. Il fait justice d'un certain nombre d'idées reçues: non, Luther n'était pas obsédé par le trafic des indulgences (la rémission des peines promise aux fidèles en échange d'argent); non, son voyage à Rome en 1510 ne fut pas aussi décisif qu'il le dit; non, il n'a pas nécessairement voulu rompre avec l'idée de catholicité.

O retrato de Lutero

(11) Para o estudo da Reforma e da Contra-reforma são fundamentais as obrasfontes seguintes: Archiv zur Weimarer Ausgabe der Werke Martin Luthers (AWA), Concilium Tridentinum. Diariorum, Actorum, Epistolarum, Tractatuum nova Collectio. Edidit Societas Goerresiana, Freiburg i. Br. 1901 ss (CT), Corpus Catholicorum (CC), Corpus Reformatorum (CR), Deutsche Geschichte in Quellen und Darstellung. vol. 3: Reformationszeit 1495-1555, ed. de Ulrich Köpf (DG), Enchiridion Symbolorum, Definionum et Declarationum de Rebus Fidei et Morum de H. Denzinger, ed. de P. Hünermann, latim-alemão, (ES), Revisionsnachtrag (RN), Weimarer Ausgabe, Schriften (WA), Weimarer Ausgabe, Briefe (WAB), Weimarer Ausgabe, Deutsche Bibel (WADB), Weimarer Ausgabe, Tischreden (WATR

(12) L'Histoire (Le Classique) 392 (outubro de 2013), 96. O livro de Lucien Fabvre, Martin Luther, un destin, Paris, P.U.F., traduzido para português, por exemplo em 1994 por Fernando Tomaz, Porto, Asa, tem um posfácio de Robert Mandrou. No texto Chapoutot alude ao livro de J. Delumeau, Le péché et la peur. La culpabilisation en Occident XIIIe-XVIII siècles, Paris, Fayard, 1984, 369-624, no qual o autor revela mais uma vez o seu interesse pelo tema. Editou em 1978 La Peur en Occident (XIVe-XVIIIe siècles). Une cité assiégée, ibid. 
Febvre brosse le portrait d'un Luther humain, trop humain, vulgaire et intelligent, angoissé et courageux. C'est bien l'histoire d'un homme, et non d'un géant, que l'auteur retrace: celle d'un moine préoccupé par son salut et qui, ne trouvant pas les réponses à ses questions dans la doctrine d'une Église qui exploite ce que Jean Delumeau appellera la "pastorale de la peur», en vient à prôner, après tant d'autres, la réforme. Febvre présente donc Luther comme le parfait exemple d'un processus d'individuation qui voit la naissance de l'individu.

\section{Linhas de força do livro febvriano}

Le «destin» de Martin Luther est cependant né de la rencontre entre la piété tourmentée, parfois désespérée, d'un homme seul face à son péché, et des désirs et peurs d'un monde, celui du Saint Empire romain germanique du XVIe siècle, dont le livre fait la biographie. Febvre sait en décrire les forêts profondes et les villes industrieuses, où se côtoient des princes volontiers las de la tutelle impériale et romaine, un peuple porté à l'eschatologie messianique et des prélats bien trop gourmands des biens de ce monde. Alors que le thème de la «reforme» est presque aussi vieux que l'Église elle-même, Febvre montre comment, en rencontrant l'Allemagne de son temps, Luther a provoqué, à son corps défendant, la Réforme, ce grand schisme d'Occident.

\section{Que resta?}

Lucien Febvre livre ici une certaine idée de la biographie, qui allie le plaisir du roman servi par un historien-écrivain, et le sérieux de la science; qui conjugue histoire sociale, politique, économique et culturelle. Certes, ce texte de 1928 est daté: la recherche a depuis nuancé ce portrait de l'Allemagne moderne, et certains propos sentent leur époque et son essentialisme («Luther est en toutes choses de sa race et de son pays. Il est, foncièrement, un Allemand»...).

\section{O contexto histórico}

Mais, dans un contexte qui n'y était guère favorable, Febvre montre que, tout en étant soucieux de se mêler à la vie, l'historien sait se placer au-dessus de la mêlée: professeur à Strasbourg, l'auteur se garde de tout portrait à charge de l'Allemagne, et s'abstient de tout commentaire lors de la réédition de 1944, attitude notable qui contraste avec celle des patriotes de la Grande 
Guerre, engagés dans le procès du germanisme éternel, ou des nationalistes des années 1920 et 1930, aux lunettes embuées de germanophobie ${ }^{(13)}$.

De uma importância particular se reveste o discurso do Papa Bento no convento de Erfurt, em de Novembro de 2011, aquando da sua viagem à Alemanha (22-25 de Setembro de 2011), no encontro com os representantes do Conselho da Igreja Evangélica Alemã, que afirmou a certa altura sobre as motivações de ordem espiritual que levaram Lutero a reagir e a afirmar uma nova visão da essência do cristianismo:

Was ihn umtrieb, war die Frage nach Gott, die die tiefe Leidenschaft und Triebfeder seines Lebens und seines ganzen Weges gewesen ist. „Wie kriege ich einen gnädigen Gott“: Diese Frage hat ihn ins Herz getroffen und stand hinter all seinem theologischen Suchen und Ringen. Theologie war für Luther keine akademische Angelegenheit, sondern das Ringen um sich selbst, und dies wiederum war ein Ringen um Gott und mit Gott.

Mais adiante falou da espiritualidade cristocêntrica de Lutero:

Luthers Denken, seine ganze Spiritualität war durchaus christozentrisch: «Was Christum treibet», war für Luther der entscheidende hermeneutische Maßstab für die Auslegung der Heiligen Schrift. Dies aber setzt voraus, daß Christus die Mitte unserer Spiritualität und daß die Liebe zu ihm, das Mitleben mit ihm unser Leben bestimmt.

\section{As investigações sobre a Idade Média e o conhecimento do passado. A herança medieval de Lutero e a teologia monástica e mística}

Será muito diferente a comemoração de 2017 comparada com as evocações anteriores, em especial as de 1617 e de 1917 que consagraram Lutero como reformador tipo profeta e como herói nacional. Como já se

(13) Além dos livros de Lortz e Jedin e outros, lembramos o de Y. Congar (1983), Martin Luther, sa foi, sa reforme, e quase à distância de cem anos em relação a Lucien Febvre os dos cardeais R. Marx, arcebispo de Munique-Freising e presidente da Conferência Episcopal Alemã e das Comissão Episcopais da Comunidade Europeia (COMECE). e W. Kasper, cardeal emérito da Cúria e outrora presidente do Conselho Pontifício para a Unidade dos Cristãos: respetivamente, Kirche überlebt (2015) e Martin Luther. Eine ökumenische Perspektive (2016). 
disse atrás, rasgaram-se novos horizontes sobre o agostinho Martinho e a Reforma e também sobre a Igreja de Roma.

O resultado da investigação histórica sobre a Idade Média contribuiu em muito e de muitas formas para mudar a perceção do passado:

A Idade Média tardia já não é vista como um período histórico totalmente obscuro, como muitas vezes foi representado pelos protestantes, mas também não é concebido como plenamente luminoso como sucedeu nas antigas descrições católicas. Esta época aparece hoje como tempo de grandes contrastes: de devoção exterior e de profunda interioridade, de teologia orientada para as obras no sentido do do ut des e de absoluta convicção da total dependência do homem da graça de Deus; de indiferença relativamente às obrigações religiosas - mesmo aqueles relativos ao ofício eclesiástico - e de profundas reformas, como em algumas ordens monásticas. A Igreja não era uma realidade monolítica, pois no corpus christianum conviviam teologias, estilos de vida e concepções da Igreja muito variadas e diversificadas. Os historiadores dizem que o séc. XV foi uma época de especial fervor religioso na Igreja. Durante este período cada vez mais leigos tiveram a possibilidade de receber uma boa instrução, o que fez nascer neles o desejo de ouvir sermões mais perfeitos e de uma teologia que os ajudasse a levar uma vida cristã condigna. Lutero aproveitou estas correntes teológicas e devocionais e desenvolveu-as depois.

Também as investigações históricas católicas acerca de Lutero levaram a concluir que ele era uma personalidade de intenso fervor religioso e um homem rigoroso na oração. A literatura católica sobre Lutero foi durante quatro séculos influenciada por Johannes Cochlaeus, conselheiro do duque Jorge de Saxónia e adversário de Lutero, seu contemporâneo ${ }^{(14)}$ : o

(14) Johannes Cochläus (Breslau, 1479-1552), humanista e teólogo, também conhecido por Dobeneck, que de amigo passou a inimigo acérrimo de Lutero. Escreveu Brevis Germaniae descriptio tum a rebus gestis moribusque populorum tum a locorum situ, mas foram os seus Commentaria de actis et scriptis Martini Lutheri que se tornaram mais célebres. Esta obra marcou profundamente a opinião anti-Lutero que perdurou durante séculos. Ver Remigius Bäumer, «Cochläus, Johannes», Theologische Realenzyklopädie (TRE) 8, De Gruyter, Berlim/Nova Iorque 1981, 140-146; Theodor Kolde, "Cochlaeus; Johannes», Realenciclopädie für protestantische Theologie und Kirche (RE) 4, Leipzig; J. C. Hinrichs, 3. ${ }^{a}$ ed., 1898, 194-200. 
papel de Cochlaeus na divulgação da figura do Reformador como relata o documento em apreço:

Cochlaeus retratou Lutero como um monge apóstata, um destruidor da cristandade, um corruptor da moral e um herege. O resultado desta primeira reaproximação com a figura de Lutero, crítico mas compreensivo, foi o de libertar os estudos católicos de uma apreciação unilateral própria daquelas obras polémicas sobre Lutero. Lúcidas análises históricas realizadas por outros teólogos católicos mostraram que o que conduziu à divisão da Igreja não foram as questões cruciais de que se ocupou a Reforma, como a doutrina da justificação, mas antes as críticas movidas por Lutero à situação da Igreja do seu tempo, que tinham origem no estado de decadência em que se encontrava.

Ao chamar a atenção para a análise histórica católica de Lutero o texto diz que o passo sucessivo foi a individuação da presença dos conteúdos análogos existentes em estruturas e sistemas de pensamento teológico diversos, em especial através de um confronto sistemático entre os teólogos mais representativos das duas confissões: Tomás de Aquino e Martinho Lutero.

Na Idade Média houve não poucas reformas monásticas, tendo sido o movimento mais importante no séc. $\mathrm{X}$ o que surgiu na Abadia de Cluny. No Concílio de Constança (1414-1418)(15) falou-se da reforma da Igreja «na cabeça e nos membros» e um documento amplamente difundido, intitulado Reformacion keyser Sigmunds, invocava o retomar de uma ordem justa em todos os aspetos da vida. Em finais do séc. XV a ideia de avançar com reformas chegou aos governos e às universidades. Valla ao contestar a autenticidade da Donatio Constantini (313) rasgou novos horizontes sobre a ideia reinante da cristandade como entidade dominadora e acima do poder temporal. Tal ideia perdurou até ao Vaticano II que, pela primeira vez, sancionou oficialmente a liberdade religiosa e de consciência, e Paulo VI suprimiu o índice de livros proibidos

(15) Ao Concílio de Constança que condenou Huss e Wiclef seguiram-se os de Florença (1439-1445) e o 5. ${ }^{\circ}$ de Latrão (1512-1517) sob Júlio II (1503-1513) e Leão X (15131521). Ficou célebre a comissão «Reformatio de emendanda Ecclesia» de que faziam parte vários cardeais. O Consilium de emendanda Ecclesia de 1537 constitui o relatório final, mas que na prática não obteve qualquer resultado de destaque, ao mesmo tempo que a Reforma avançava a passos gigantescos. Roma permanecia indiferente ao que estava a acontecer. 
A teologia monástica e mística é objeto de análise nos nº. 99-101. A figura de Agostinho e o regresso à Sagrada Escritura e aos Padres da Igreja estavam presentes no espírito de muitos que viam a estrutura da Igreja afastada do Evangelho e da pureza original do cristianismo.

Relativamente a Lutero diz o Do Conflito à Comunhão:

Lutero estava também profundamente enraizado na tradição mística do período tardo-medieval. Encontrou inspiração e apoio nos sermões alemães de João Tauler († 1361) e sentiu-se em grande sintonia com eles. Além disso publicou o texto místico Theologia deutsch (1518), escrito por um autor desconhecido, o qual teve larga difusão na Alemanha graças à publicação feita por Lutero.

Tauler insere-se na série de místicos que apareceram quando a Escolástica se encontrava em profunda decadência e a vida eclesiástica conhecia uma fase bastante crítica, mais voltada para os aspetos terrenos e mundanos do que para a autenticidade evangélica. A letra sufocava o espírito. Sobressaíram mulheres como as três Catarinas, de Siena, de Bolonha e de Génova, Brígida da Suécia e Juliana de Norwich, que mostraram a sua enorme insatisfação quanto ao estado em que se encontrava a Igreja. Mas foi na Alemanha em especial que surgiram figuras de proa imbuídas do desejo de modificar a situação. Lembramos os Gottesfreunde, Eckart, Tauler e Suso. Importante foi a teologia alemã ou Der Frankfurter, publicado pela primeira vez em $1516^{(16)}$. Nos Países Baixos destacou-se Ruusbroec (1293-1381) e a «Devotio moderna» a partir de finais do séc. XIV tornou-se um movimento relevante de renovação da espiritualidade nos Países Baixos e na Alemanha norte-ocidental. De lembrar ainda Geert Groote de Deventer (1340-1384) e os irmãos da vida comum, a congregação de Windesheim, comunidade reformada de Cónegos Regrantes Agostinhos, percursora de Lutero, do Calvinismo e de Erasmo. Os ideais de Windesheim, duramente atacados no Concílio de Constança pelos dominicanos, foram defendidos com vigor pelo célebre chanceler da Universidade de Paris entre 1395 e 1415, teólogo, pregador e homem político, Jean Gerson (1363-1429). Pensadores como Huss e Wiclef, condenados por heresia, manifestaram a premente necessidade de operar grandes reformas no seio da Igreja e fora dela.

(16) Christian Peters, «Theologia deutsch», Theologische Realenzyklopädie, 33 (2002), 258-262. 
Os humanistas que apelavam ao regresso às fontes, à Sagrada Escritura e aos Padres da Igreja, defendiam o contacto direto com os textos originais aos quais aplicavam o método histórico-filológico e crítico, pondo de parte a Vulgata de S. Jerónimo. Além da intenção de chegarem à pureza dos textos primitivos movia-os o propósito de uma renovação profunda da Igreja. Podemos considerar Lefèvre d'Étaples em França, Erasmo nos Países Baixos e Reuchlin na Alemanha como os protótipos dessa tendência que depressa lançou raízes um pouco por toda a parte ${ }^{(17)}$.

\section{Conclusão}

No termo deste trabalho a questão essencial que se coloca é esta: quem foi Martinho Lutero? Ulrich Köpf no seu excelente livro Martin Luher. Der Reformator und sein Werk começa por dizer que Melanchton descreve Lutero como instrumento sagrado de Deus e que muitos dos seus contemporâneos o consideravam homem de Deus comparável aos profetas Elias ou Daniel.

Depois da sua morte, iniciou-se a discussão acerca do autêntico Lutero, a qual durou até ao séc. XX. Prevalecia, contudo, a ideia nacionalista do "Lutero alemão" e do libertador do cristianismo. Mas vinha ao de cima o facto de ele ter sido condenado como herege e passado por falsificador e corrupto. O livro de Cochlaeus teve uma enorme influência na difusão da ideia destruidora do antigo monge agostinho. Os juízos eram positivos e negativos. Köpf concorda com o documento Do Conflito à Comunhão, ao escrever que no séc. XX, mercê de investigações aprofundadas, se pode concluir que o filho de Eisleben era fruto dos ideais renovadores que remontam a finais da Idade Média

(17) Alguns humanistas alemães - em Wittenberg: Lutero (1483-1546); Heidelberg: Oekolampadius (1482-1531) e Melanchton (1497-1560); Erfurt: Reuchlin (1455-1522), Staupitz (c. 1468-1524), Huten (1488-1523) e Eck (1486-1543); Freiburg: Peutinger (14651547); Augsburgo: Pirckeimer (1470-1573); Leipzig: Emser (1478-1527); Tübingen e Basel: Wimpfeling (1450-1528), Meissen e Cochlaeus (1479-1552); Nürnberg: Bucer (1491-1551). E ainda: Agricola, Aventinus, Bebel, Brant, Vom dem Busche, Celtis, Divaeus, Franck, Gebwiler, Heresbach, Hessus, Von Hutten, Krantz, Meisterlin, Münster, Von Neuenahr, Nauclerus, Beatus Rhenanus, Rufus, Sabinus, Schedel e Sleidan, Spiegel. - Ver Wilhelm Kühlmann et alii, ed. (2005-2011), Die deutschen Humanisten. Dokumente zur Überlieferung der antiken und mittelalterlichen Literatur in der Frühen Neuzeit, Turnhout, Brepols, 3 vols. em 4 ts. 
e que a sua espiritualidade, apesar de algumas atitudes incorretas, como a sua postura extremamente hostil aos judeus.

Com Lutero nasceu uma perspetiva nova acerca da relação de Deus com o homem e da liberdade de pensamento, da valorização da Palavra revelada e da espiritualidade.

Köpf a terminar a sua análise encarece o papel que a Reforma teve no campo cultural, particularmente no que concerne à língua alemã.

Eine der grössten Begabungen Luthers lag in seinem Umgang mit der Sprache, vor allem mit seiner Muttersprache. Durch seine zahlreichen deutschen Schriften, vor allem aber im jahrzehntelangen Ringen um eine deutsche Bibelübertragung hat Luther wesentlich zur Entstehung einer einheitlichen deutschen Schriftsprache beigetragen. Zur Wirkung seiner Deutschen Bibel in weiten Kreisen kam die seiner Kirchenlieder und seiner beiden Katechismen, die seine Gedanken weit über jene Gebiete verbreiteten, die sich der Wittenberger Reformation geöffnet hatten. Über seine zeitgebundenen Züge wie seine gewaltige Wirkung in der Vergangenheit hinaus gehört Luthers Werk zu jenen grossen sprachlichen Hinterlassenschaften, mit denen man sich immer wieder beschaftigen kann, um immer neue Entdeckungen zu machen. Geduldiger Lektüre erschliessen sich ihre Schätze: ein Reichtum an Gedanken und Formulierungen zu vielen Themen des menschlichen Lebens und eine religiose Tiefe, die Luther eine einzigartige Stellung in der neueren Geschichte zuweisen ${ }^{(18)}$.

É neste contexto de reavaliação das fontes da Reforma e da Contrareforma que se situa o diálogo ecuménico e se inserem os estudos dos cardeais alemães W. Kasper e R. Marx, os quais já citámos anteriormente, e de teólogos e pensadores das duas áreas em confronto.

De referir igualmente o interessante livro Disputationen. Teil: 1, Reflexionen zum Reformationsjübiläum 2017. Nachdruck von Beiträgen aus Politika \& Kultur, Zeitung des Deutschen Kulturrates" (2. a ed. revista e aumentada,

(18) Tem aumentado nas últimas décadas o número de livros e artigos sobre Lutero e a Reforma, sobretudo na Alemanha, da autoria de prestigiados autores como K. Aland, H. G. Anderson, O. Bayer, A. Beutel, H. Bornkamm, M. Brecht, Ch. Burger, I. Dingel, G. Ebeling, B. Hamm, P. Henning, H. P. Jüngens, H. Junghans,W. Card. Kasper, Th. Kaufmann, U. Köpf, K. Lehmann, M. Lienhard, B. Lohse, R. Card. Marx, B. Moeller, G. Müller, T. A. Murphy, H. A. Oberman, W. Pannenberg, O. H. Pesch, H. Schilling e R. Schwartz, para só mencionar alguns. 
Berlin, Deutscher Kulturrat e. V.), editado em 2015 por O. Zimmermann e Th. Geissler; e o lúcido artigo de G. Panmi SJ, «Cattolici e Luterani. L'ecumenismo nel"Ecclesis sempre reformanda'», publicado no penúltimo número de La Civiltà Cattolica (Roma 3985, 9 de julho de 2016, 17-25).

Mas nas ingentes tarefas que o diálogo luterano-católico exige há um elemento relevante: a memória que registou os factos ocorridos ao longo de cinco séculos tempo e que agora os coloca à consideração de todos para serem revistos e reapreciados. O prémio Nobel da paz, Elie Wiesel (1928-2016), falecido no passado dia 2 de julho, que sobreviveu ao Holocausto, sempre defendeu a ideia de que não se pode viver sem o passado: «Se esquecemos o passado, a humanidade fica mutilada», disse numa entrevista a Le Figaro em 1998. Nesse ano organizou um convénio internacional sobre «Memória e história», promovido pela Academia universal das culturas a que presidiu desde 1993, movido pela intenção de lutar contra a xenofobia, o antissemitismo e toda e qualquer forma de discriminação. Aliás a memória faz parte da tradição bíblica e da literatura judaica, em especial da Mishná e do Talmud e de tantos escritores medievais e posteriores como Hannah Arendt.

O Papa Francisco ao receber o prémio Carlos Magno em maio passado, desenvolveu o tema "Que coisa te aconteceu, Europa?», tendo recordado os pais fundadores da Europa: Schuman, Adenauer e De Gasperi, que sonharam uma Europa assente em princípios e valores que colocavam à frente da «res» económica e financeira. O Bispo de Roma citou Wiesel usando a expressão «transfusão da memória», que lhe era tão cara. Lembrava o Papa Bergoglio que a memória «nos liberta daquela tendência actual muitas vezes mais atraente de fabricar com rapidez sobre as areias movediças dos resultados imediatos que poderão tornar-se numa conquista política fácil, rápida e efémera, mas que não realizam a plenitude humana».

Repetindo a citação do documento Do Conflito à Comunhão:

O que aconteceu no passado não pode ser alterado. Mas aquilo que se recorda do passado e o modo como sucedeu, pode no decurso do tempo ser modificado. A recordação torna presente o passado. Enquanto o passado é imutável, já a presença do passado no presente pode ser alterada. Olhando para 2017 trata-se não de escrever outra história, mas de a narrar de outra forma (II, 16). 
Concluímos com um depoimento de Reinhard Marx inserto na publicação do Deutscher Kulturrat, Politik \& Kultur (4, 2015). Marx afirmou que Martinho Lutero não quis a divisão da Igreja; o que sucedeu foi que «a mensagem do Evangelho tinha sido e continuava a ser deturpada» e que ele pretendia recuperar o seu carácter original. Acrescentou que passados 50 anos de diálogo ecuménico é possível ler os textos de Lutero e extrair deles preciosos ensinamentos, pelo que nunca será exagerado sublinhar a impressionante evolução verificada nestas cinco décadas.

Decorridos 500 anos continua a tentar-se definir a personalidade de Lutero. Alguém afirmou: Lutero mais do que doutor ou teólogo foi um profeta. Mas, como sabemos, a mensagem profética inclui conteúdos e exigências que nem sempre se vislumbram à primeira vista, se é que alguma vez se consegue penetrar neles em toda a sua plenitude por se inserirem na esfera do insondável.

\section{Abreviaturas}

Archiv zur Weimarer Ausgabe der Werke Martin Luthers (AWA)

Concilium Tridentinum. Concilium Tridentinum. Diariorum, Actorum, Epistolarum, Tractatuum nova Collectio (CT)

Corpus Catholicorum (CC)

Corpus Reformatorum (CR)

Deutsche Geschichte in Quellen und Darstellung. vol. 3: Reformationszeit 1495-1555, ed. de Ulrich Köpf (DG)

Enchiridion Symbolorum, Definionum et Declarationum de Rebus Fidei et Morum de H. Denzinger, ed. de P. Hünermann, tatim-alemão (ES) Revisionsnachtrag (RN)

Weimarer Ausgabe, Schriften (WA)

Weimarer Ausgabe, Briefe (WAB)

Weimarer Ausgabe, Deutsche Bibel (WADB)

Weimarer Ausgabe, Tischreden (WATR) 